\author{
Zava, Marco A. ; Sansiñena, Marina
}

\title{
Buffalo dairy production: a review
}

\section{Postprint de la colaboración en la obra: \\ The buffalo (Bubalus bubalis) : production and research / Giorgio A. Presicce (ed.). Bentham Science, 2017}

Este documento está disponible en la Biblioteca Digital de la Universidad Católica Argentina, repositorio institucional desarrollado por la Biblioteca Central "San Benito Abad". Su objetivo es difundir y preservar la producción intelectual de la Institución.

La Biblioteca posee la autorización del autor para su divulgación en línea.

Cómo citar el documento:

Zava, MA; Sansiñena M. Buffalo dairy production : a review [en línea]. En: The buffalo (Bubalus bubalis) : production and research / Giorgio A. Presicce (ed.). Bentham Science, 2017. http://dx.doi.org/10.2174/97816810841761170101 Disponible en: http://bibliotecadigital.uca.edu.ar/repositorio/investigacion/buffalo-dairy-production-review.pdf [Fecha de consulta: ....] 